\title{
Chiapter 58 \\ ON THE EFFECT OF CONFIGURATIONS OF THE COAST ON THE STORM SURGES IN THE ISE BAY
}

\author{
Kiyoshi Tanaka \\ Prof. of the OSAKA UNIV., Dr. Eng., \\ Aki ra Murnta \\ Assist. Prof. of the OSARA UNIV., \\ Osaka, Japan
}

INTRODUCTION

Wind drift is generally considered as the predominant factor of the storm surge along the sea coast. Authors noticed the fact that the duration of the wind blow of any direction is not long even at a big typhoon, while the storm surges more than $2 \mathrm{~m}$ are sometimes observed in the interiors of Osaka-, Ise-, and Tokyo-bay, and they have studied on another factor which might cause such water rise.

A hump of water caused by a low atomospheric pressure transmits in the manner of a long wave and is deformed under the topographical effect when it comes into a bay. Authors are intending to show that the build-up of water due to topographical effect is sometimes larger than that occurring by wind drift.

In this paper, the calculation was carried on neglecting the effect of wind drift and its result was compared with the observed value.

TOPOGRAPHICAL DATA OF THE ISE-BAY AND OBSERVED HEIGHTS OR THE METEOROLOGICAL TIDE BY THIS TYPHOON

Contour lines of the bottom of the Ise-bay are shown in the Fig. 5-1, in which the water depth under the datum level (D.L.) is indicated in meter Considering the pattern of these contours and of wave crests shown in the refraction diagram, the axis of this bay and vertical sections orthogonal to it are determined as shown in the Fig. 5-1 with chain-lines. The moving direction of this typhoon in this area was about $N 25^{\circ} \mathrm{E}$ as shown also in the same figure.

Sectional area : $A$, width of the bay : $B$, and mean water depth : $H_{0}$ $\left(\approx_{A_{0}} / \mathrm{B}_{\mathrm{o}}\right)$ rela ting to the distance from the inlet of the bay are given together in Fig. 5m.

To make the calculation simple, we may assume $\mathrm{H}_{0}$ to be constant ( $\mathrm{H}_{0} \fallingdotseq$ $2.5 \mathrm{~m}$ ) from No. 2 to No. 4 section and decrease linearly from No. 4 toward 
the inner.

Precise observations of the height of the storm surge could not be co' lected, but only the approximate values are shown in Fig. 5 -3 at present, in which $\zeta$ is the maximm deviation from the astronomical tidal stage. The deviation at Nagoya harbor $(\zeta \fallingdotseq 3.5 \mathrm{~m})$ is the largest one ever recorded in Japan.

\section{BUILD UP OF A LONG WAYR DUE TO GRADUAL VARIATIONS OF SECTIONAL AREA OP THB BAY}

For the change of heights of a long wave in the variable section, thes is a well-known formula (Green's law). (See, for instance, Lamb : Hydrody. namics 6 th ed., p. 274, for detailed derivation.)

$$
\zeta / \zeta_{*}=\left(B_{*}^{2} H_{*} / B^{2} H\right)^{1 / 4}
$$

where $\zeta$ : the wave-height of a long wave,

B : the width of the channel,

i : the water depth before reaching of waves,

and the subscript * refer to the value in the initial section.

In our calculations, the static water depth (H) may be taken as follon considering that the time variations of the astronomical tide are generally much slower than those of the storm surge.

$$
H \equiv H_{0}+h
$$

where $\mathrm{H}_{0}$ : the water depth under the datum level,

h : the height of the astrononical tide above the datum level.

$H_{0}$ and $h$ in each station are shown in the Table 5-1, respectively.

The ratio $S / \zeta_{\star}$ and $B_{\star}^{2} H_{\star} / B_{H}^{2}$ computed from the Fig. 5-2, 5-3 and the Table 5-1, are plotted in a $\log -\log$ diagram. (Fig. 5-4) In this figure, we see that the Green's law is applicable for the region between No, 5 and No. 8 section (at the inner part of tnis bay). While, between No. 2 and No 5 (at the inlet and middle part of the bay), $S / S$ * seems to be proportiona to $\left(B_{*} H_{*} / B^{2} H\right)^{3 / 3}$, and the increment of height in this region is greater than that predicted by the Green's formula.

These results may be interpreted as follows. In the inner part of thi bay, the configuration of the coast forms some typical wedge-shape. Due to the comparatively small surface area of this region, the wind effect may be secondary and the effect of the configuration of the coast may be so primar in this inner region that toe Green's law will be applicable. While in the outer part of the bay, the surface area is much larger than the inner part and the wind effect may be more dominant and the increase of tidal height will be larger than that predicted only by the effect of the bay configuration. 


\section{ON THE EFFECT OF CONFIGURATIONS OF THE COAST ON THE STORM SURGES IN THE ISE BAY}

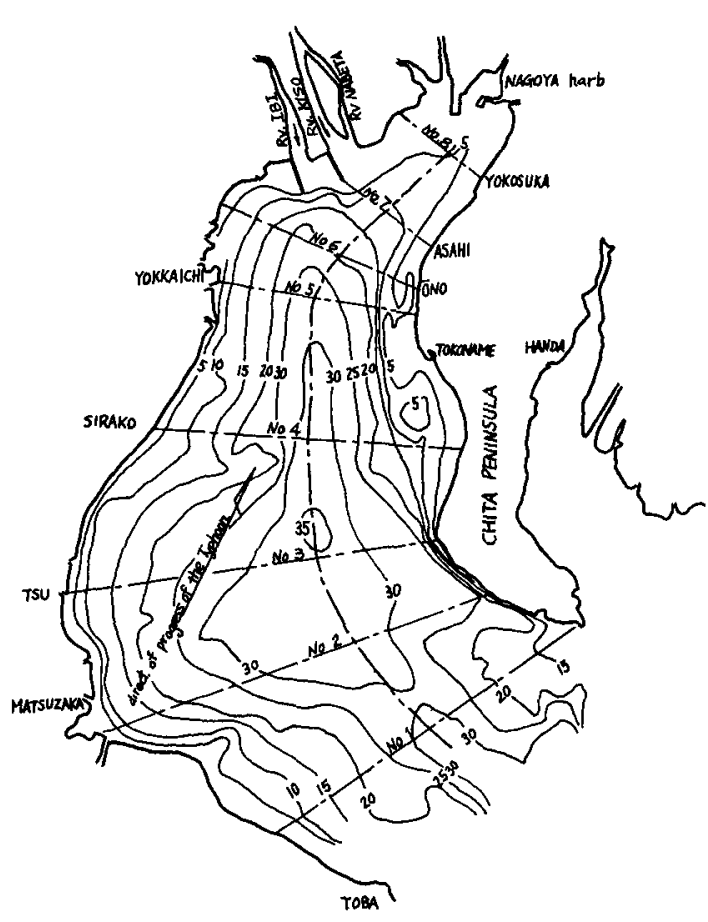

Fig. 5-1

The configuration of the Isembay

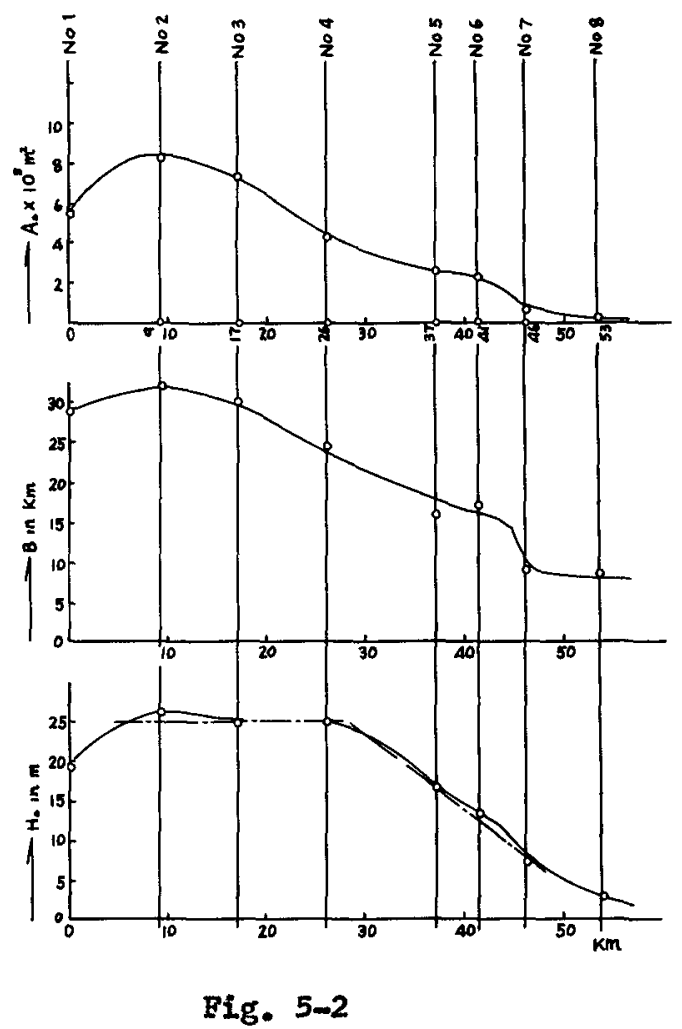

Sectional area, width and mean waterdepth at each section.

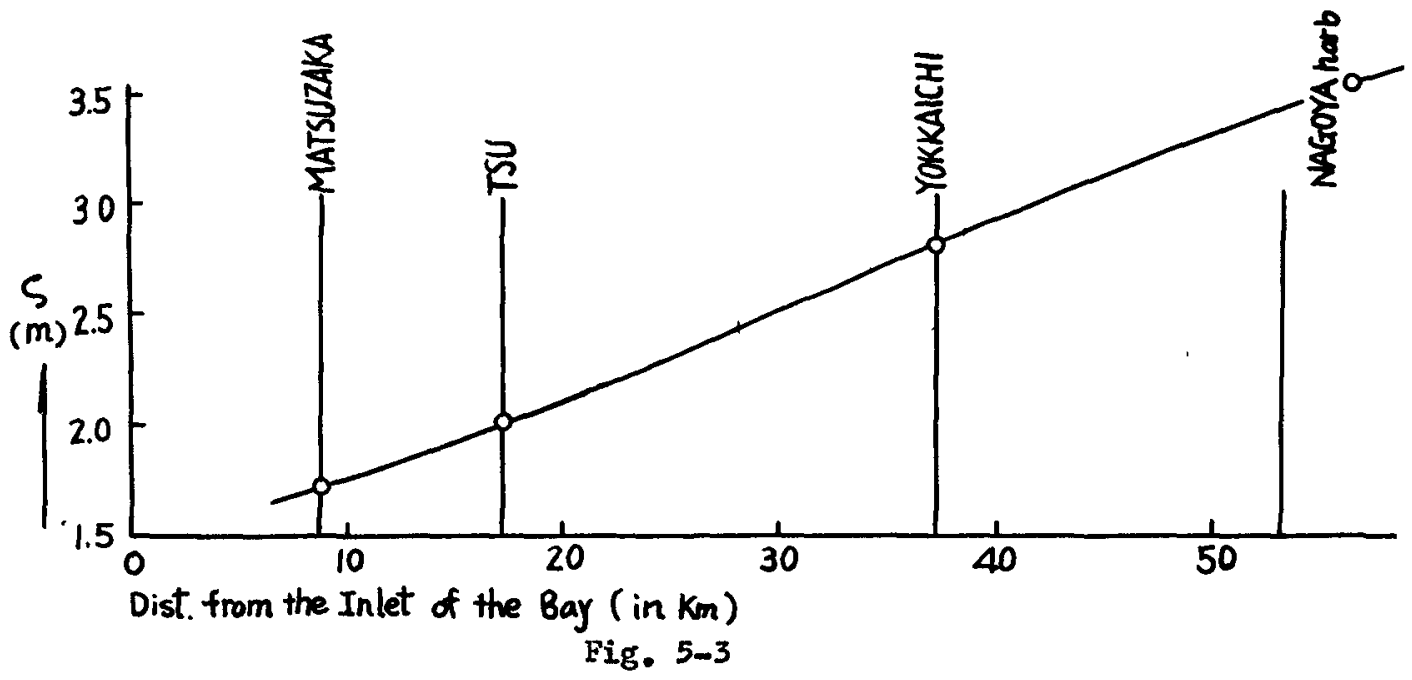

Observed heights of the storm surge along the coast of the Ise-bay 
COASTAL ENGINEERING
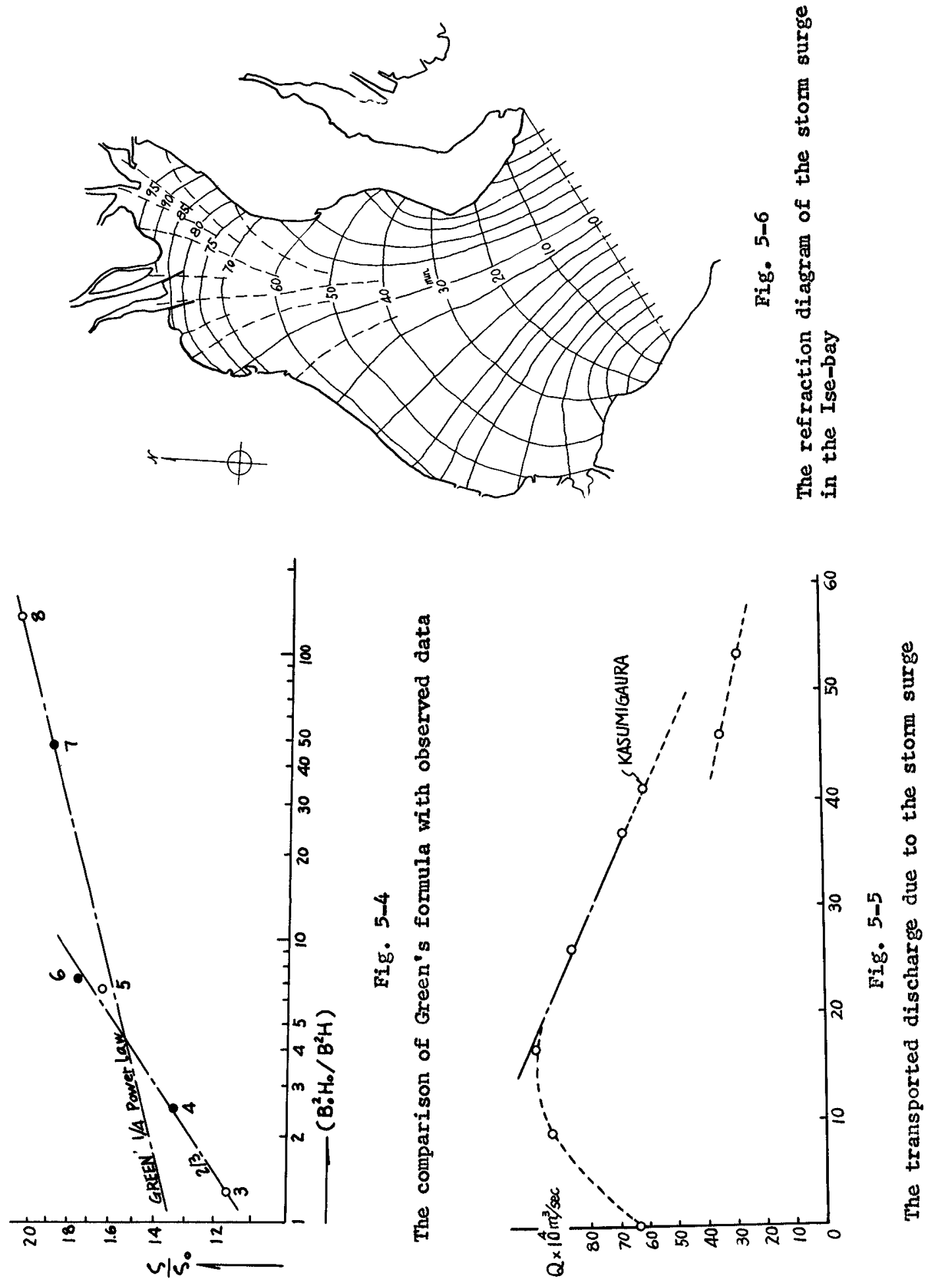


\section{ON THE EFFECT OF CONFIGURATIONS OF THE COAST ON THE STORM SURGES IN THE ISE BAY}

THE MASS TRANSPORTATION BY THE STORM SURGE

The long waves with finite amplitude, as already mentioned, always accompany the substantial mass transportation. The particle velocity and the relative and absolute propagation speed of the long waves are given theoretically as follows. (See, for instance, Lamb : Hydrodynamics 6 th ed., P. 278 - 279.)

$$
\begin{aligned}
& u=2\left\{\sqrt{g\left(H_{0}+\zeta\right)}-\sqrt{g H_{0}}\right\}, \\
& \omega=\sqrt{g\left(H_{0}+\zeta\right)} \\
& \Omega=u+\omega=3 \sqrt{g\left(H_{0}+\zeta\right)}-2 \sqrt{g H_{0}}
\end{aligned}
$$

where $u$ : the particle velocity due to long waves,

$\omega, \Omega$ : the relative and absolute propagation velocity, respectively,

$H_{0}$ : the undisturbed water depth, and

$\zeta$ : the elevation above $H$ due to the wave.

These values are calculated by using topographical and observed data an are shown in the Table 5-1.

According to these calculations, the particle velocity of long wave is about $1.0 \mathrm{~m} / \mathrm{sec}$ in the inlet or middle region of the bay, while in the inner part it reaches $3-4 \mathrm{~m} / \mathrm{sec}$.

It must be noticed that when the undisturbed depth is small and the wave height is comparatively large, the particle velocity of a long wave is often equivalent to the relative propagation velocity and so we can't neglec the former.

The substantial mass transport due to particle transitions (u A) are shown in the Table 5-1, and the Fig. 5-5. In the Fig. 5-5, we see that the transported mass increases gradually from the inlet to No. 3 section and decrease almost linearly from No. 3 to No. 5 section. A sudden decrease is observed at the mouth of the Ibi or Kiso River. We must notice that, in our analysis, the crest of the long wave is just rooting and so $\partial \zeta / \partial t \fallingdotseq$, then the discharge must be constant theoretically. Therefore, these change of discharge must be paradoxical, but the reason for this discrepancy may be as follows.

(1) nergy dissipations by the bottom friction are not considered in this analysis.

(2) Sectional area of the bay are treated, for simplicity, as the rectangular and so the change of sectional area according to the variation of free surface (i.e. the intrusion discharge running over the shore) are not considered.

(3) Like above, the intrusion going up the river is not treated in this considerations.

These factors will contribute for the tidal discharge to decrease. Even by these rather rough first approximation, the substantial velocity with the storm surge is decidedly supposed to be so large that we cannot neglect the dynamic behaviour of the storm surge. 
COASTAL ENGINEERING

Table 5-1

\begin{tabular}{|c|c|c|c|c|c|c|c|c|c|}
\hline No. of Section & 1 & 2 & 3 & 4 & 5 & 6 & 7 & 8 & 9 \\
\hline $\begin{array}{c}\text { The name of places } \\
\text { on the section }\end{array}$ & $\begin{array}{l}\text { The Tip of } \\
\text { chita Pen. }\end{array}$ & $\begin{array}{c}\text { Matsu- } \\
\text { zaka }\end{array}$ & Tou & Sirako & Yokkaichi & $\begin{array}{l}\text { Kasumi- } \\
\text { Ga-ura }\end{array}$ & Asahi & $\begin{array}{c}\text { Dkada- } \\
\text { gawa }\end{array}$ & $\begin{array}{l}\text { Nagoja } \\
\text { Hab. }\end{array}$ \\
\hline $\begin{array}{c}\text { Cumulative Diøt. } \\
\text { from the } \mathrm{No} .1 \text { Sect. } \\
\text { in } \mathrm{Km}\end{array}$ & 0 & 9 & 17 & 26 & 37 & 41 & 46 & 53 & 58 \\
\hline $\begin{array}{l}\text { Sactional Area } \\
\text { under the Datum } \\
\text { in } \mathrm{Km}\end{array}$ & 554 & 836 & 741 & 428 & 262 & 225 & 63 & 23 & - \\
\hline $\begin{array}{l}\text { Width of the Sect. } \\
\text { in Km }\end{array}$ & 29 & $B_{*} 32$ & 30 & 25 & 16 & 17 & 9 & 8 & - \\
\hline $\begin{array}{l}\text { Hean Depth under the } \\
\text { Datum in } A / B \text {, } \\
\text { in } \mathrm{m}\end{array}$ & 19.1 & 26.1 & 247 & 174 & 164 & 13.2 & 7.0 & 28 & - \\
\hline $\begin{array}{l}\text { Hight of the Astron. } \\
\text { ride over the Datum: } \\
h \text {, in m }\end{array}$ & 15 & 1.6 & 1.6 & 1.6 & 1.7 & 1.7 & 1.7 & 1.7 & 1.7 \\
\hline $\begin{array}{l}\text { Mar, Deviat. of the } \\
\text { Mateor, tide : } \\
\text { in a }\end{array}$ & 1.6 & $S^{5 *}, 7$ & 2.0 & 2.3 & 2.8 & 2.7 & 32 & 3.4 & 3.55 \\
\hline $\begin{array}{l}8(h+h) \\
\text { in } m / s e c\end{array}$ & 143 & 16.5 & 16.1 & 13.7 & 13.3 & 12.1 & 9.2 & 66 & \\
\hline $\begin{array}{c}\text { Relative Propag.Vela } \\
\text { a } \mathrm{g}(\mathrm{H}+\mathrm{h}+\mathrm{)} \\
\text { in } \mathrm{m} / \mathrm{sec}\end{array}$ & 14.8 & 17.0 & 16.7 & 14.5 & 143 & 13.1 & 10.8 & 8.8 & \\
\hline $\begin{array}{c}\text { Absolute Propag. Velof } \\
=\mathrm{u}+ \\
\text { in } \mathrm{w} / \mathrm{sec}\end{array}$ & 15.8 & 18.0 & 17.9 & 16.1 & 16.3 & $|5|$ & 14.0 & 13.2 & \\
\hline $\begin{array}{c}\text { Particle Velo. } \\
\text { u } \\
\text { in } \mathrm{m} / \mathrm{sec}\end{array}$ & 1.0 & 1.0 & 1.2 & 1.6 & 20 & 2.0 & 3.2 & 4.4 & \\
\hline $\begin{array}{c}\text { Transport. Discharge } \\
\text { in } 10^{8} \mathrm{~m} / \text { sec }\end{array}$ & 62.7 & 94.0 & 1018 & 85.1 & 66.9 & 60.0 & 34.3 & 27.8 & \\
\hline
\end{tabular}




\section{ON THE EFFECT OF CONFIGURATIONS OF THE COAST \\ ON THE STORM SURGES IN THE ISE BAY}

REFRACTION OF THE LONG NAVE IN THE ISE-BAY

Regarding the storm surge as the long wave, we can draw the refraction diagram and investigate the convergence or divergence of wavemenergy and other characters.

The Fig. 5-6 is the refraction diagram in the Ise-Bay assuming the straight crest at the inlet (No. 1 section), and using the Arthur-MunkIssacs' method. From this figure, the energy of storm surge seems to concentrate near Tsu and Tokoname and expands near Sirako and Matsuzaka. (These trends approximately correspond to the actual damage.)

The time required for the surge crest to propagate from the inlet (the tip of the Chita Peninsula) to the Nagoya harbor, is about 100 minutes by our calculations. The comparison with the occurred phenomena could not be done because of the lack of observation. 
Chapter 59

A SYSTEM OF RADIO-LOCATION USED IN THE DELTA AREA

\author{
R.H.J. Morra \\ Hydraulic Division of the Delta Works, \\ Rijkswaterstaat, The Hague.
}

\title{
INTRODUCTION
}

In the South-Western part of the Netherlands the Delta project is being carried out consisting inter alia of 4 main dams closing 4 large inlets (fig.1). Through the four tidal inlets to be closed about 1800 million cubic metres of water run into the Delta area during flood tide and flow out again during ebb tide. This means about 7000 million cubic metres daily.

The bottom of the inlets and the sea-bottom consist of fine sand $\left(d_{50}=.100-.300 \mathrm{~mm}\right)$, which is in constant movement. During the past centuries considerable changes in the bottom contour have taken place. Yearly many millions of cubic metres of sand are moved by the water. The bottom is a very complicated system of gullies and sandbanks which has evolved down the centuries and is ever changing. It is evident that the dams under construction will out off the tidal flow into and out of the area and that this will result in a considerable change in the sand movement.

The underwater estuary extending as far as $20-25 \mathrm{~km}$ seawards from the dams will probably have to adapt itself rather suddenly, i.c., within a few decennia. This can be dangerous for the Western extremities of the islands. The whole combination of phenomena concerned has to be studied and watched very carefully.

Basic information concerning the sand movement and its consequences is given by soundings.

A long term of frequent and accurate soundings with very good repeatability is required for the entire coastal area of the estuary. However, the meteorological conditions for sounding are such that good conditions only obtain on about 20 days a year, because good visibility and a quiet sea must occur simultaneously. Moreover, there is a serious shortage of landmarks and at distances seawards of less than $10 \mathrm{~km}$ from the shore visual location is impossible. The only solution is to make the location independent of visibility. For these reasons it was decided that a system of radio-location should be devised. We were advised by an independent expert to adopt the Decca survey system.

With such a system it is possible to make frequent soundings with very good repeatability and with a reasonably fow number of launches, because many more suitable days (and nights) become available. This system of radio-location is called the Delta chain. The system is also used for special purposes (velocity and sand transportmeasurements). 